\title{
Optimization and Application of Flue Gas Denitrification Control for Thermal Power Units Based on Internal Model Control
}

\author{
Gao Song \\ State Grid Shan Dong Electric Power Research Institute \\ Jinan, China \\ e-mail: gaosong163mail@163.com
}

Gao Bo

Shandong Shengli Steel Pipe Co., Ltd

CityZibo, China

e-mail: 13573158636@163.com

\author{
Pang Xiangkun \\ State Grid Shan Dong Electric Power Research Institute \\ Jinan, China \\ e-mail: dkymxr@163.com \\ Meng Xiangrong \\ State Grid Shan Dong Electric Power Research Institute \\ Jinan, China \\ e-mail: jn_xiangkun@163.com
}

\begin{abstract}
The flue gas emissions of thermal power units are widely concerned because of the increasingly strict environment protection requirements. This paper aims at the optimization of flue gas denitrification control for thermal power units. The research introduces the selective catalytic reduction flue gas denitrification system, establishes the first-order model of SPRAYING ammonia system by step response of controlled system, and determines the PID controller parameters following the internal model control tuning rule. The automatic control strategy of SPRAYING ammonia system based on internal model control is given. The application of a $300 \mathrm{MW}$ unit and a $600 \mathrm{MW}$ unit shows the effectiveness of the control strategy.
\end{abstract}

Keywords-optimization;flue gas denitrification;selective catalytic reduction;thermal power units;internal model control.

\section{INTRODUCTION}

With the increasingly strict environment protection requirements, the flue gas emissions of large scale coalfired power units are widely concerns $[1,2]$. In order to control the emission of nitrogen oxides, more and more power plants use Selective Catalytic Reduction (SCR) method [3,4], which transforms the $\mathrm{NO}_{\mathrm{X}}$ to $\mathrm{N}_{2}$ and $\mathrm{H}_{2} \mathrm{O}$ under the action of catalyst. SPRAYING ammonia flow can influence the efficiency of SCR flue gas denitrification. Too little SPRAYING ammonia flow will cause $\mathrm{NO}_{\mathrm{X}}$ exceed the standard, otherwise, excessive SPRAYING ammonia flow brings the waste of production cost, and may cause the block of air preheater. Therefore, it has important significance for the safe and economic operation of thermal power plants $[5,6]$.

Based on the internal model control, this paper aims at the optimization of flue gas denitrification control for thermal power units. First, the selective catalytic reduction flue gas denitrification system is introduced, then the firstorder model of SPRAYING ammonia system is established by step response of controlled system, and the automatic control strategy of SPRAYING ammonia system based on internal model control is given. Finally, the application of a $300 \mathrm{MW}$ unit and a $600 \mathrm{MW}$ unit shows the effectiveness of the control strategy.

The paper is organized as follows. In the next section, the SCR system is introduced and some definitions are given. In Section 3, the control model based on internal model control is presented. Section 4 presents the automatic control strategy for SCR system. In Section 5 , the application result is given to show the efficiency of the strategy. Finally, we conclude our paper in section 6.

\section{SCR FLUE GAS DENITRIFICATION}

\section{A. Formation mechanism of NOx}

First, The NOx emission has brought broad attention in the world, and the most of countries and areas has established strict regulations and standards to limit NOx emissions, so coal power stations have to put more attention to control NOx emission.

The process of nitrogen oxide formation is complicated, but at least three categories of nitric oxides formed in combustion process have been identified according to sources of the nitrogen and chemical kinetics of nitrogen oxidation, that is, (1) Thermal NOx, (2) Fuel NOx, (3) Prompt NOx.

(1) Thermal NOx

In high temperature combustion environments, the nitrogen in air can be oxidized to NOx, which is called thermal NOx. Its formation mechanism was proposed by Zeldovich[7,8]. According to the mechanism, the thermal NOx formation can be described as below:

$$
\begin{aligned}
& \mathrm{O}+\mathrm{N} 2 \rightarrow \mathrm{NO}+\mathrm{N} \\
& \mathrm{N}+\mathrm{O} 2 \rightarrow \mathrm{NO}+\mathrm{O}
\end{aligned}
$$

As shown in the formula above, the main factors which influence the thermal NOx formation are coal burning temperature, oxygen concentration and reaction time.

(2) Fuel NOx

NOx formed from the reactions of fuel nitrogen with oxygen is a principal source of NOx emission in the 
combustion of fossil fuel and is termed fuel NOx. Fuel NOx accounts for $70 \sim 80 \%$ in the total NOx formed in coal-fired boilers. It forms due to the pyrogenation and oxidation of nitrides contained in fuel. The deoxidization reaction of NO also exists at the same time. The formation and deoxidization mechanisms of fuel NOx are very complex.

\section{(3) Prompt NOx}

The mechanism of prompt NOx is different from the above two mechanisms. The $\mathrm{CH}$ radicles formed in the fuel burning impinge the $\mathrm{N} 2$ molecules to produce $\mathrm{CN}$, and which are further oxidized to form NO. The reactions occur very fast. So the NOx formed is called prompt NOx. The formation mechanism can be described as below:

$$
\begin{gathered}
\mathrm{CH}+\mathrm{N} 2 \rightarrow \mathrm{HCN}+\mathrm{N} \\
\mathrm{HCN}+\mathrm{O}(\mathrm{O} 2, \mathrm{OH}) \rightarrow \mathrm{NO}+\mathrm{H} 2(\mathrm{H})+\mathrm{CO}
\end{gathered}
$$

The temperature has little influence on the formation of prompt NOx. Comparing with the thermal and fuel NOx, the amount of prompt NOx is very small.

\section{B. Technologies for the control of NOx emissions}

A variety of technologies for the control of $\mathrm{NOx}$ emissions from coal combustion processes has been developed. These may be divided into two categories: Combustion Modification Technologies and Postcombustion Gas Treatments.

The former comprises different kinds of low NOx burning technologies, the latter includes selective catalytic reduction (SCR) technology, selective non-catalytic reduction (SNCR) technology, and advanced reburning technology which combines reburning and SNCR technology[11,12].

This paper mainly discusses the SCR flue gas denitrification method.

\section{SCR Flue Gas Denitrification}

The SCR flue gas denitrification system is as shown in Fig.1.

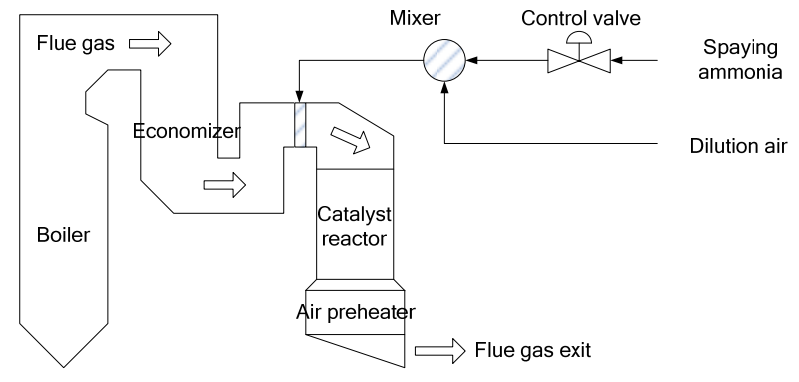

Figure 1. SCR flue gas denitrification system

The SPRAYING ammonia flow is controlled by a valve, then mixed with the dilution air, and infected into the furnace through the ammonia injection grid. The $\mathrm{NO}_{\mathrm{X}}$ and ammonia will cause the selective catalytic reduction under the action of catalyst to achieve the object of cleaning the flue gas. The major reaction process can be expressed as follows:

$$
\begin{gathered}
4 \mathrm{NO}+4 \mathrm{NH}_{3}+\mathrm{O}_{2}=4 \mathrm{~N}_{2}+6 \mathrm{H}_{2} \mathrm{O} . \\
6 \mathrm{NO}_{2}+8 \mathrm{NH}_{3}=7 \mathrm{~N}_{2}+12 \mathrm{H}_{2} \mathrm{O} .
\end{gathered}
$$

$$
\mathrm{NO}+\mathrm{NO}_{2}+2 \mathrm{NH}_{3}=2 \mathrm{~N}_{2}+3 \mathrm{H}_{2} \mathrm{O} \text {. }
$$

Excessive SPRAYING ammonia flow will cause side effect as follows:

$$
\begin{gathered}
4 \mathrm{NH}_{3}+5 \mathrm{O}_{2}=4 \mathrm{NO}+6 \mathrm{H}_{2} \mathrm{O} . \\
\mathrm{SO}_{2}+\mathrm{O}_{2}=2 \mathrm{SO}_{3} . \\
\mathrm{NH}_{3}+\mathrm{SO}_{3}+\mathrm{H}_{2} \mathrm{O}=\mathrm{NH}_{4} \mathrm{HSO}_{4} .
\end{gathered}
$$

Therefore, the SPRAYING ammonia flow is very important to the efficiency of SCR flue gas denitrification, with too little SPRAYING ammonia flow will cause $\mathrm{NO}_{\mathrm{X}}$ exceed the standard, and on the other hand, excessive SPRAYING ammonia flow brings the waste of production cost and may cause the block of air preheater.

Because of the huge devices in the SCR system, the flue gas denitrification system has characteristics of large time lag and delay. External disturbances such as load change also have significant influence on the control performance. Therefore, the optimization of the SPRAYING ammonia flow control is needed.

\section{SPRAYING AMMONIA FLOW CONTROL BASED ON IMC}

\section{A. Internal Model Control}

Internal Model Control (IMC) has advantages of high control accuracy, good robustness and anti-interference, therefore, it is widely used in the large-lag system in many industrial processes.

Consider a SISO feedback control loop depicted in Fig.2. Here $P(s)$ and $C(s)$ are the process and the PID controller, respectively; $r(t), u(t)$ and $y(t)$ are the setpoint, the control signal, and the process output, respectively.

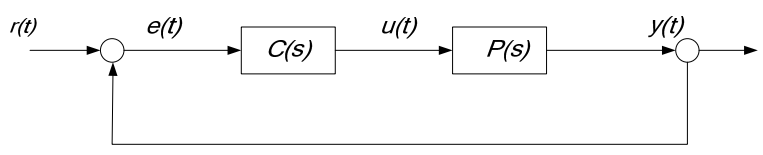

Figure 2. A SISO feedback control loop

$P(s)$ is first-order plus dead time model,

$$
P(s)=\frac{K}{T_{1} s+1} e^{-\theta s}
$$

or a second-order plus dead time model,

$$
P(s)=\frac{K}{T_{1} s^{2}+T_{2} s+1} e^{-\theta s}
$$

$C(s)$ is the PID controller,

$$
C(s)=\mathrm{K}_{p}\left(1+\frac{1}{T_{i} s}+T_{d} s\right)
$$

The PID controller setting for first-order plus dead time model as

$$
K_{p}=\frac{T_{1}}{K\left(\tau_{c}+\theta\right)}, T_{i}=T_{1}, T_{d}=0
$$

and that for second-order model as

$$
K_{p}=\frac{T_{2}}{K\left(\tau_{c}+\theta\right)}, T_{i}=T_{2}, T_{d}=\frac{T_{1}}{T_{2}}
$$

By taking the IMC tuning rule, the desired closed-loop response will be 


$$
\begin{aligned}
G_{c l}(s) & =\frac{1}{\left(\theta+\tau_{c}\right) s+e^{-\theta s}} e^{-\theta s} \approx \frac{1}{\left(\theta+\tau_{c}\right) s+1-\theta s} e^{-\theta s} \\
& =\frac{1}{\tau_{c} s+1} e^{-\theta s}
\end{aligned}
$$

The user-selected parameter $\tau_{c}$ stands for the desired close-loop time constant.

\section{B. SPRAYING Ammonia Control}

The SPRAYING ammonia control can be used as a single loop PID controller, is shown in Fig.3. To apply the internal model control, we must know the first-order model of process. We can determine the process model by the step response of the controlled system.

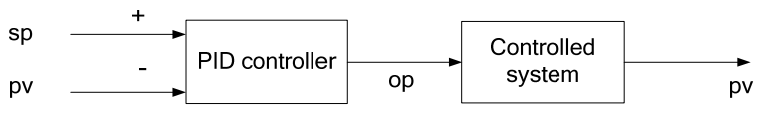

Figure 3. SPRAYING ammonia control system

Based on the IMC tuning rule, the PID parameters can be determined by Equation (9) and Equation (10), with the desired close loop time constant $\tau_{c}$ is selected by users to adjust the performance of PID controller. The close loop time constant is shown in Fig.4.

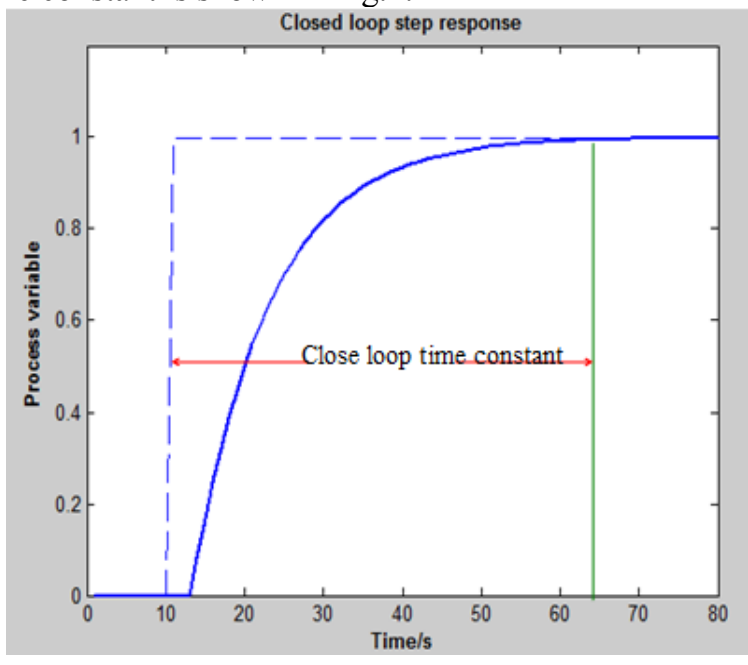

Figure 4. Close loop time constant

The controlled system is used as first-order model in Equation (7), and $K, T_{1}, \theta$ can be determined by the step response of the controlled system as following steps.

The algorithm of determining PID parameters is given as folloews.

Step1: In a steady state, step change the instruction of control valve by $\triangle O P$, then wait the controlled system tends to a next steady state. The change of process value is $\Delta p v$, then the proportional gain $K$ is determined by

$$
K=\Delta p v / \Delta o p \text {. }
$$

Step2: the start time of step change is $t_{1}$, and the end time that system tends to next steady state after step response is $t_{2}$, then $T_{1}$ is determined by $T_{1}=t_{2}-t_{1}$.
Step3: the pure lag time constant $\theta$ is determined by the time-lag characteristics of the physical devices. In general, we can set parameter $\theta$ by experience.

\section{FLUE GAS DENITRIFICATION CONTROL BASED ON IMC}

Based on the IMC tuning rule, the flue gas denitrification control strategy is given as follows in Fig.5.

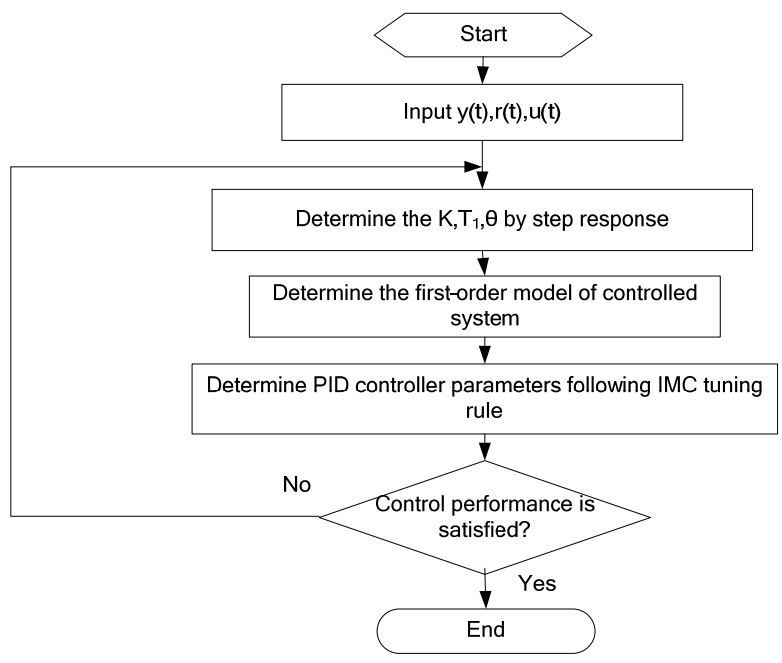

Figure 5. Flue gas denitrification control strategy

\section{APPLICATION}

The flue gas denitrification control strategy based on internal model control is used in Shandong Laicheng \#4 300 MW power unit and Shandong Liaocheng \#1 600 MW power unit. The application result is shown in the following table.

TABLE I. APPLICATION RESULT OF FLUE GAS DENITRIFICATION CONTROL

\begin{tabular}{ccccc}
\hline No. & $K$ & $T_{1}$ & $\theta$ & $\begin{array}{c}\text { NOx } \\
\text { emissions }\end{array}$ \\
\hline $\begin{array}{c}\text { Laicheng \#4 300 } \\
\text { MW power unit } \\
\text { Liaocheng \#1 600 } \\
\text { MW power uint }\end{array}$ & 1.21 & 174.4531 & $20 \mathrm{~s}$ & 67.32 \\
\end{tabular}

After the optimization of control strategy, the average value of NOx emissions of Laicheng 300 MW power unit is $67.32 \mathrm{mg} / \mathrm{m}^{3}$, and the average value of NOx emissions of Liaocheng $600 \mathrm{MW}$ power unit is $73.61 \mathrm{mg} / \mathrm{m}^{3}$, which is less than national standard $100 \mathrm{mg} / \mathrm{m}^{3}$. It can be seen that the proposed algorithm is feasible and effient.

\section{CONCLUSION}

The research introduces the SCR flue gas denitrification system, and establishes automatic control strategy of SPRAYING ammonia system based on internal model control. The application of a $300 \mathrm{MW}$ unit and a $600 \mathrm{MW}$ unit shows the effectiveness of the control strategy. The next work is to study the action of feed forward control of unit load to the flue gas denitrification control policy. 


\section{REFERENCES}

[1] YANG Dong, XU Hong. Discussion on the application of the SCR technology in coal-fired power plants [J]. Electric Power Technology and Environmental Protection, 2007, 23(1): 49-51.

[2] ZHU Lin, WU Bi-jun, DUAN Jiu-xiang, et al. Situation of production and application on selective catalytic reduction fuel gas de-NOx catalysts [J]. Electric Power, 2009, 42(8): 61-64.

[3] WANG Hai. Operation optimization of SCR denitration system of 1000 MW unit boiler[J].Zhejiang Electric Power, 2013, 32(12):5558.

[4] YANG Wei-juan, ZHOU Jun-hu, LIU Jian-zhong, et al.Application of selective catalyst reduction (SCR) denitrification technology for utility boilers [J]. Thermal Power Generation, 2005(9): 10-14.

[5] LIANG Chuan, SHEN Yue. Optimal operation of selective catalytic reduction (SCR) flue gas denitrification system in 1000 MW unit [J]. Electric Power, 2012, 45(1): 41-44.

[6] DU Zhen, QIAN Xu-yue, HE Sheng, et al. Analysis and optimization for operating costs of gas SCR DeNOx in coal-fired power plants [J]. Electric Power, 2013, 46(10): 124-128.
[7] Yan Weiping. Electricity generation technology using cleaned coal [M]. Bei Jing : China Electric Publishing Company, 2002.

[8] Cen Kefa, Yao Qiang, et al. Combustion theory and pollution control[M].Bei Jing : Mechanical Industrial Publishing Company, 2004.

[9] Liu Zhichao. Test and analysis on the factors influencing NOx emission of coal boilers[J]. Power System Engineering, 2005, 21(5):30-34

[10] Zhou Xingang, Liu Zhichao, et al. Research and test for reducing NOx emission of boiler by combustion regulation [J].Power System Engineering, 2005,21(5):16-18.

[11] An En-ke,Shi Meng, et al. Uitra low NOx emission control of utility boiler with high combustion efficiency[J].Boiler Technology, 2006,37(2):71-75.

[12] Cheng Hui, Xie Yonggang, et al. Present and trend of flue gas DeNOx technology in coal-fired power plant[J].Zhejiang Electric Power, 2005,2,38-40. 